Anuario de

Derechos Humanos 2005 


\section{Reabrir y Cicatrizar: Notas sobre el Informe Valech y sus Reacciones}

\author{
Lucas Sierra I.*
}

\begin{abstract}
Estas notas se refieren a la forma en que la Comisión Valech encaró el desafío que le plantearon los conceptos de prisión política y tortura. Se refieren también al carácter no jurisdiccional que tuvo la Comisión, y a la relación que es posible trazar entre dicho carácter y el discutido "valor probatorio" de su informe. Acto seguido, estas notas vinculan dicho valor probatorio a las reacciones que el informe produjo en las instituciones armadas y en la Corte Suprema. Por último, discuten la reacción del público al informe y, comparándola con la que el público tuvo frente al Informe Rettig, sugieren una tendencia generalizada que valora la sedimentación de la verdad y sus terapéuticas consecuencias sociales.
\end{abstract}

\section{Introducción}

L a Comisión Nacional sobre Prisión Política y Tortura (conocida como Comisión Valech) entregó su informe al Gobierno el 10 de noviembre del año 2004. Este, a su turno, lo dio a conocer al público el 28 del mismo mes, subiéndolo inmediatamente a internet. Un intenso debate siguió.

La Comisión había sido creada un año antes, el 11 de noviembre de 2003, por el Decreto 1.040 del Ministerio del Interior. Se creó como órgano asesor del Presidente de la República y tuvo un doble propósito: (1) Determinar las personas que sufrieron privación de libertad y torturas por razones políticas, por actos de agentes del Estado o de personas a su servicio, en el período comprendido entre el 11 de septiembre de 1973 y el 10 de marzo de 1990; y (2) Proponer al Presidente de la República criterios de reparación para esas personas.

Ante la Comisión se presentaron los casos de 35.868 personas, de las cuales 27.255 fueron calificadas como víctimas. Los nombres de todas estas víctimas se incorporaron a una lista que acompañó al informe. Respecto de estas personas y del ordenamiento jurídico, la Comisión propuso, además, ciertos criterios de reparación. Algunos fueron pronto materializados por la Ley 19.992 de diciembre de 2004, aprobada rápida y unánimemente por las dos cámaras del Congreso.

\section{Desafíos conceptuales}

La tarea encomendada a la Comisión planteó una serie de problemas y desafíos. Por lo pronto, la Comisión debió dar un significado plausible

\footnotetext{
* Abogado, Universidad de Chile. Profesor de Derecho en esa universidad e investigador del Centro de Estudios Públicos ("CEP"). Miembro de la Comisión Nacional sobre Prisión Política y Tortura. Estas notas son a título personal del autor y no representan necesariamente el pensamiento de esa Comisión.
}

Este comentario está disponible en formato digital en www.anuariocdh.uchile.cl 
a los conceptos de prisión política y tortura. El decreto que creó la Comisión entregó algunas pistas generales:

- La privación de libertad o la tortura, o ambas si fuera el caso, debían haber obedecido a razones políticas;

- Los victimarios debían ser agentes del Estado o personas a su servicio, entendiéndose por tales aquellos particulares que, sin tener calidad de agentes del Estado, actuaban con conocimiento, tolerancia, aquiescencia o en connivencia con éstos, sin que se precise una relación formal o de orden contractual; y

- Los hechos debían haber acaecido entre el 11 de septiembre de 1973 y el 10 de marzo de 1990.

El decreto impuso estos requisitos básicos e hizo, además, ciertas exclusiones: no podían ser calificadas como víctimas "las personas privadas de libertad en manifestaciones públicas, que fueron puestas a disposición de los tribunales de policía local o de algún tribunal del crimen por delitos comunes y luego condenadas por estos delitos". También fueron excluidas las personas que fueron objeto de "retenciones" temporales efectuadas durante allanamientos masivos, operaciones "peineta", u otra forma similar de control colectivo o indiscriminado de la población. Por último, también fueron excluidas las personas calificadas por la Comisión de Verdad y Reconciliación (la Comisión Rettig), estos es, aquellas personas que fueron ejecutadas o desaparecidas entre 1973 y 1990.

\section{Prisión política}

Con estos parámetros, la Comisión intentó un concepto de prisión política. Lo primero que consideró fue la existencia de "motivación política" en la privación de libertad. Al respecto, señala el informe: "La motivación política no siempre es evidente y, de hecho, la actividad represiva siempre buscó respaldo en la supuesta defensa de la seguridad del Estado, del orden público, de la lucha contra el terrorismo, etc." A fin de distinguir la motivación política en medio de este bosque de juricidad -o de aparente juricidad- la Comisión consideró como prisión política los actos represivos ejecutados en virtud de normas que proscribían la actividad política en cuanto tal. Un buen ejemplo de esto fueron las detenciones hechas en virtud del Decreto Ley 77 de 1973, que declaró como asociaciones ilícitas a los partidos políticos que habían pertenecido a la Unidad Popular.

En este mismo sentido, la Comisión calificó como prisión política los actos ejecutados en razón de medidas privativas de libertad sin juicio o sin un fundamento razonable, como las detenciones administrativas, o la aplicación de medidas restrictivas o privativas de libertad una vez cumplidas las condenas; en virtud de las atribuciones de los estados de excepción constitucional. Cabe recordar el carácter doblemente excepcional de estos estados de excepción debido, entre 
otras cosas, a su extensión en el tiempo y a la ausencia de un mínimo control democrático a la hora de ser decretados y renovados.

También la Comisión consideró como prisión política hechos acaecidos en un contexto jurisdiccional, tales como la aplicación de normas jurídicas por parte de un tribunal en forma patentemente arbitraria o con fines evidentes de represión política. Ejemplos típicos fueron aquí los procesos seguidos ante la justicia militar, primero en la forma de tribunales de guerra luego del Golpe en 1973, y después como jurisdicción militar estable durante los años 1980. Como lo muestran los casos extractados en el informe, el razonamiento desplegado por los jueces militares, en especial por los Consejos de Guerra en la primera época, trasunta ideología política y mucha arbitrariedad, algo muy lejano de los principios de tipicidad y legalidad con los que desde la Codificación se ha intentado limitar la discreción judicial. Después, durante los 80, los principios del debido proceso fueron largamente ignorados en los procesos seguidos ante las Fiscalías Militares. Largos períodos de incomunicación y el paso previo por los cuarteles de la Central Nacional de Informaciones (CNI) facilitaban esa ignorancia. Cuando estas circunstancias fueron acreditadas a la Comisión, el caso fue calificado como prisión política.

\section{Tortura}

La Comisión intentó también definir un concepto plausible de tortura. No fue una tarea fácil: un simple maltrato se convierte en tortura a lo largo de un continuo difícil de precisar. El contexto, además, es muy importante: los golpes dados por un policía uniformado a un detenido al subirlo a un furgón policial y al bajarlo de éste en un cuartel policial, en democracia, no son del todo iguales a los mismos golpes dados por un agente de civil al subirlo vendado a un auto sin identificación y al bajarlo en un recinto secreto de detención, en dictadura.

La Comisión fundió las definiciones de "tortura" contenidas en dos documentos del derecho internacional: La Convención contra la Tortura y otros Tratos o Penas Crueles, Inhumanos o Degradantes, de la ONU, y la Convención Interamericana para Prevenir y Sancionar la Tortura, de la OEA. Ambas fueron promulgadas por Chile el 26 de noviembre de 1988. Esta es la definición: "Constituye tortura todo acto por el cual se haya infligido intencionadamente a una persona dolores o sufrimientos graves, ya sean físicos o mentales, con el fin de obtener de ella o de un tercero información o una confesión, castigarla por un acto que haya cometido o se sospeche que ha cometido, intimidar o coaccionar a esa persona u otras, anular su personalidad o disminuir su capacidad física o mental, o por razones basadas en cualquier tipo de discriminación. Siempre y cuando dichos dolores o sufrimientos se hayan cometido por un agente del Estado u otra persona a su servicio, o que actúe bajo su instigación, o con su consentimiento o aquiescencia".

La Comisión intentó allegar la mayor cantidad de información posible sobre la tortura. Los testimonios de todas las víctimas que declararon 
haberla sufrido (más del 90\%) fueron ordenados y sistematizados. De este modo, y gracias a la convergencia de innumerables relatos, la Comisión pudo reconstruir patrones de conducta en torno a la tortura. Estos patrones, a su turno, permitieron dar o no credibilidad a quienes declararon haber sido torturados, pues no hay razones para no creer en un testimonio consistente con dicho patrón de conducta.

Con todo, el hecho de la tortura no fue determinante para la calificación de una persona como "víctima" por parte de la Comisión. Consciente de que, por regla general, la tortura no deja huellas visibles, menos después de 30 años; y consciente, también, de sus limitadas capacidades probatorias, la Comisión reconoció como víctimas a quienes lograron probar ante ella el hecho de haber sufrido prisión política, sin exigírsele, además, la prueba de su tortura.

Desde un punto de vista probatorio, la prisión política y la tortura se encuentran en lados opuestos. En la enorme mayoría de los casos, la prisión política fue acreditada mediante documentos. Se trataba de certificados entregados por los propios organismos captores, de bandos aparecidos en la prensa, de expedientes judiciales, de listas producidas por las Fuerzas Armadas, etc. Además, esta información estaba complementada por la contenida en los archivos de las instituciones que estuvieron, principalmente, del lado de las víctimas, como el Comité por la Paz, la Vicaría de la Solidaridad o la Cruz Roja. Como se comprenderá, no hay certificados de tortura entregados por los propios torturadores. En ciertos casos, hay otros certificados, como algunos expedidos por médicos o algunas querellas por tortura presentadas en la época. Pero en la inmensa mayoría de los casos, y a diferencia de la prisión política, la denuncia de tortura carece de prueba documental. Carece, asimismo, de otros medios probatorios, como la prueba de testigos (por regla general, se torturó fuera de la vista de terceras personas). Aquí vale, básicamente, el testimonio del denunciante y su coherencia con el relato de otros denunciantes. Esto ayuda a explicar la exclusión de la tortura a la hora de la calificación de una persona como víctima.

Además de ser enormemente útil para dicha calificación, el carácter intensamente documental de la prisión política sirvió para procesar en un tiempo relativamente corto (un año) la gran cantidad de casos que procesó la Comisión. Las múltiples y diversas fuentes documentales de información permitieron formar una nutrida base computacional de datos. Ella ayudó a recolectar y cruzar antecedentes con velocidad.

\section{Labor no jurisdiccional}

Las precauciones tomadas de cara a la tortura y su prueba, tuvieron que ver con el carácter de la tarea encomendada a la Comisión. El decreto que la fundó fue explícito al señalar que: "En el cumplimiento de su objeto, la Comisión no podrá, de manera alguna, asumir 
funciones de carácter jurisdiccional y, en consecuencia, no podrá pronunciarse sobre la responsabilidad que con arreglo a la ley pudiera caber a personas individuales por los hechos de que haya tomado conocimiento." La Comisión, por tanto, no fue un tribunal. Fue un órgano asesor de la política.

Al no ser un tribunal, la Comisión quedó fuera de las exigencias procedimentales que impone la garantía constitucional del debido proceso. Una de estas exigencias es la Ilamada "bilateralidad de la audiencia": las dos partes, acusadora y acusada, deben tener el mismo conocimiento básico de lo que ocurre en el proceso y la misma posibilidad básica de adelantar su defensa. Muchas personas que concurrieron a la Comisión indicaron el nombre de quienes denunciaban haberlas torturado. A pesar de las protestas de algunas organizaciones, la Comisión se reservó esos nombres. Como no fue un tribunal, la Comisión no llamó ni menos oyó a los denunciados, quienes nunca fueron emplazados. Estos, por tanto, no tuvieron la oportunidad de imponerse de los cargos hechos en su contra ni de defenderse, por lo que dar a conocer sus nombres hubiera sido un acto de grave injusticia.

Si se piensa en el especial carácter de la tarea que realizó la Comisión, el tiempo transcurrido desde los hechos que investigó y el número de casos que debió conocer, no debería extrañar el hecho de que una parte del debate que siguió a su publicación se haya concentrado en su "valor probatorio". Es decir, en cuánta verdad puede esperarse de los hechos narrados por el informe.

Como se explicó más arriba, del hecho de la prisión política, generalmente certificado de manera oficial, la Comisión tuvo certeza. Del hecho de la tortura, se adquirió lo que ella y la Comisión Rettig Ilamaron "convicción moral". En otras palabras, la plausibilidad de hechos denunciados en conformidad a un patrón general y el traslado de la carga de la prueba a quien cuestione esa plausibilidad. Obviamente, el informe no hace "plena prueba", no, al menos, en el sentido jurisdiccional del término, y la Comisión nunca esperó que la hiciera'

\section{Reacciones}

A mi juicio, con todo, hay un elemento externo que parece darle una validez especial al trabajo de la Comisión y a su informe: las respuestas con que reaccionaron las Fuerzas Armadas, Carabineros, Investigaciones y la Corte Suprema. Estas instituciones aparecen seriamente implicadas en los hechos que narra el informe $y$, no obstante haber sido sentadas en el banquillo de los acusados, su inmediata reacción no fue descalificar, sino que admitir y, con intensidad variable, lamentar lo ocurrido ${ }^{2}$.

Pionero en este reconocimiento fue el General Cheyre, Comandante en Jefe del Ejército, quien, incluso antes de que el informe fuera entregado al Gobierno, señaló el camino que después seguirían las
1 Una encuesta del Centro de Estudios Públicos (CEP) hecha poco después de haberse publicado el Informe, interrogó sobre éste y sobre su "valor probatorio." Preguntó: "Hace pocos días el Presidente dio a conocer el Informe sobre Prisión Política y Tortura. ¿Ud. cree que lo que se dice ahí respecto de las detenciones y la tortura...?" La alternativa "es verdadero" alcanzó un $48,8 \%$ de las respuestas, la alternativa "tiene algo de verdad, pero hay mucha exageración y mentira" alcanzó un 28,4\%, la alternativa "no es verdadero" sólo un 4,9\%, y no sabe/no contesta un $17,8 \%$. En alguna medida, estos resultados reflejan los problemas mencionados en torno a la prueba de la tortura. Véase Centro de Estudios Públicos (CEP), Estudio Nacional de Opinión Pública n. 20, Tercera Serie, diciembre 2004, Documento de Trabajo $\mathrm{n}$. 358, enero 2005. También disponible en www.cepchile.cl Más abajo vuelvo sobre esta encuesta.

2 Las reacciones institucionales que se transcriben a continuación están en "Informe de la Comisión Nacional sobre Prisión Política y Tortura, y respuestas institucionales", en Estudios Públicos n. 97, Verano 2005, pp. 295 y ss. Disponible también en www.cepchile.cl 
demás instituciones armadas. En una inserción publicada en el diario La Tercera el 5 de noviembre de 2004, escribió:

El Ejército de Chile tomó la dura pero irreversible decisión de asumir las responsabilidades que, como institución, le cabe en todos los hechos punibles y moralmente inaceptables del pasado. Además, ha reconocido en reiteradas oportunidades las faltas y delitos cometidos por personal de su directa dependencia; las ha censurado, criticado públicamente y ha cooperado permanentemente con los tribunales de justicia para, en la medida de lo posible, contribuir a la verdad y a la reconciliación. Asimismo, se ha condolido por los sufrimientos de las víctimas de estas violaciones, reconociendo que recibieron un tratamiento que no se condice con la doctrina permanente e histórica de la institución. Unas violaciones que no justifica y respecto de las cuales ha hecho y seguirá haciendo esfuerzos concretos para que nunca más vuelvan a repetirse. Expresión de esta línea de conducta ha sido nuestra concurrencia a la Mesa de Diálogo y el esfuerzo de recopilación de información útil y conducente para establecer el destino final de los detenidos desaparecidos, así como su remisión a los tribunales, únicos encargados de establecer la verdad jurídica y aplicar la legislación vigente. Y al mismo estilo de conducta ha correspondido, más recientemente, nuestro decidido compromiso y colaboración con la Comisión Nacional sobre Prisión Política y/o Tortura, cuyo contenido y conclusiones asumiremos con la misma serenidad y responsabilidad con que hemos actuado hasta ahora.

Cinco días después de esta declaración, el informe fue entregado al Gobierno. Antes de que éste lo hiciera público, el Director General de la Policía de Investigaciones de Chile, Arturo Herrera, hizo la siguiente declaración pública el 13 de noviembre del año 2004:

El país ha ido reconociendo progresivamente su verdad sobre las violaciones a los derechos humanos ocurridas durante un período prolongado de tiempo... En los contenidos de esa verdad se señalan prácticas institucionales y conductas de integrantes de esta Policía, que constituyeron graves crímenes contra los derechos fundamentales que se derivan de la dignidad humana... Es válido señalar que nuestra Institución no concurrió con su pequeña fuerza, ni con sus armas ni hombres, al quiebre de la democracia chilena. Como todas las reparticiones públicas, la Policía de Investigaciones de Chile debió acatar las condiciones impuestas hace 31 años. En ese contexto, no fuimos ajenos a actos que causaron daño, dolor y sufrimientos extremos a muchas personas... En virtud de lo expresado, como Director General considero necesario asumir dichas verdades de la historia social de nuestro país y, consecuentemente, solicito el perdón de todos los compatriotas.

Dos semanas después, el 28 de noviembre, el informe fue hecho público por el Gobierno. El 30 de noviembre, la Armada, Carabineros y la Fuerza Aérea hacen lo suyo. Dijo la Armada:

La Armada de Chile en general acoge con generosidad y cristiana humildad el Informe de la Comisión Nacional sobre Tortura y Prisión Política... Aceptamos como verdaderos todos los testimonios, aun cuando dada la naturaleza de la Comisión no es posible exigirle la rigurosidad propia de un proceso judicial; ni tampoco la Armada posee archivos con informaciones que permitan ratificar o desmentir las denuncias registradas... 
No obstante, independientemente de las observaciones procesales que pudiera merecer el Informe, su lectura es impactante y conmovedora, y nadie podría desconocer que en Chile se violaron gravemente los Derechos Humanos y la dignidad de muchas personas inocentes, por parte de Agentes del Estado. En este contexto, algunos miembros de la Armada, desviándose de la recta doctrina, también participaron en estos luctuosos hechos, particularmente durante los primeros meses inmediatamente posteriores al 11 de Septiembre de 1973. Al respecto, la Institución deja expresa constancia que jamás ha validado y ni siquiera insinuado la aplicación de tortura. La violación de los Derechos Humanos nunca ha sido una política Institucional. No obstante, a la luz de los testimonios recogidos por la Comisión, no podemos sino reconocer que en la cadena jerárquica de quienes estaban encargados de los procesos de interrogación, hubo personas y mandos que cometieron, autorizaron o simplemente permitieron que en los recintos de detención a su cargo ocurrieran tan lamentables hechos. Por otra parte, la Institución se hace un deber en expresar que lamentamos profundamente la violación de los Derechos Humanos y de la dignidad de las personas, en cualquier lugar y bajo cualquier circunstancia, pero particularmente delicado es que ellas hayan ocurrido a bordo del B.E. "Esmeralda", que es todo un símbolo para Chile entero. Fue desafortunado que ese buque haya sido utilizado como centro de detención, aun cuando hubiese sido sólo por dos semanas. Peor todavía que se hubiese constituido a bordo una unidad especial para interrogar bajo tortura a los detenidos.

Carabineros de Chile, a su turno, expresó:

Carabineros de Chile valora el trabajo realizado por la Comisión... Hoy, después de 30 años y con la perspectiva que da el tiempo, Carabineros se hace cargo de su historia y estima que las acciones de represión política, prisión y tortura, descritas en el Informe, nunca debieron realizarse porque son contrarias a su esencia y misión. 4. Con lo anterior, Carabineros repudia que personal de sus filas tuviese participación en casos de violaciones a los derechos humanos, donde se cuentan personas que ejercían el mando jerárquico y que tuvieron responsabilidad por acción u omisión. La Institución adhiere el sentir de las víctimas de prisión política y torturas y al de sus familias y comparte, una vez más, el sentimiento generalizado de la sociedad chilena de condena a estos dolorosos hechos.

Por último, la Fuerza Aérea:

La Fuerza Aérea de Chile, hace ya más de una década, reconoció la existencia y lamentó las violaciones a los Derechos Humanos que se informaron en la Comisión Nacional de Verdad y Reconciliación, manifestando que hechos de esa naturaleza nunca debían volver a repetirse... La Fuerza Aérea de Chile valora el trabajo efectuado por la Comisión Valech, toda vez que constituye un avance significativo en el proceso de la reconciliación nacional. Asimismo, lamenta y se conduele profundamente que compatriotas hayan sido privados de su libertad ilegítimamente y sufrido torturas, condenando con fuerza las violaciones a los Derechos Humanos cometidas, porque nada puede justificarlas... El contenido del informe de la Comisión compromete a la Fuerza Aérea, en consideración a la extensión de las situaciones que describe, como también por la tardanza de algunos niveles de mando en la adopción de medidas destinadas a reafirmar la vigencia de los derechos fundamentales de la persona. Lo expresado anteriormente no se inscribe en la tradición histórica 
de la Institución y tampoco en la aplicación de la recta doctrina... El Alto Mando de la Fuerza Aérea asume esta dolorosa verdad y reitera su compromiso para que actos de esta naturaleza nunca vuelvan a repetirse.

Tras esta batería de reconocimientos, Ilegó el turno de la Corte Suprema. Su reacción era muy esperada, pues, al igual que al Informe Rettig, al Informe Valech subyace un juicio especialmente negativo de la pasividad de los tribunales superiores frente a la sistemática violación que en sus derechos fundamentales sufrieron muchas personas. Como se viene haciendo desde hace siglos, las víctimas del poder político miraron a los jueces superiores como la última tabla oficial de salvación. Desde hace siglos éste es, precisamente, el sentido del recurso de amparo o habeas corpus. Los jueces, sin embargo, miraron para otro lado. De todas las reacciones institucionales al informe, la de la Corte Suprema fue la más ambigua:

... los miembros actuales de esta Corte Suprema... consideran que no es posible sustraerse de la gravedad de esos sucesos y sus dolorosas secuelas y dejan constancia pública de su consternación ante dichas situaciones, que se suman a otras que el Poder Judicial ha podido conocer, juzgar y sancionar en estos últimos años; Que muy distinto es el parecer de la Corte sobre los reproches genéricos que se vierten en el mismo informe en relación con el Poder Judicial, en especial, cuando se afirma que en el periodo más crítico, inmediatamente posterior al 11 de septiembre de 1973, habría existido de parte de los tribunales o de los ministros de la Corte Suprema de la época, una suerte de connivencia con quienes cometieron los excesos y violaciones que se han conocido. Esto importa un grave cargo, que carece de sustento objetivo en el propio informe y que no es posible aceptar, ya que no existen antecedentes fidedignos ni es verosímil sostener que distinguidos magistrados se hayan podido concertar con terceros para permitir detenciones ilegitimas, torturas, secuestros y muertes... Pero, en rigor y cierto es, que durante gran parte del periodo que estuvo suspendida la vigencia de la institucionalidad en el país, a partir de Septiembre de 1973, los jueces y los tribunales superiores se vieron, en gran medida, impedidos de cumplir a cabalidad con esa función... Que si bien en una perspectiva histórica distinta, es dable sostener que los tribunales pudieron tratar de llevar a cabo una acción más eficaz en la protección de los derechos individuales, no es menos cierto que las limitaciones de hecho y de derecho a que se vio sometido el pleno ejercicio de la función conservadora en aquella época, obligan a reconocer también que probablemente ello no habría tenido resultados significativos...

A pesar de su carácter más ambiguo, me parece que la reacción de la Corte Suprema es muy interesante, en especial las últimas líneas recién transcritas. En ellas se ve un reconocimiento de los jueces tan implícito como autoinculpatorio: no hicimos lo suficiente y, si hubiésemos hecho algo más, tampoco habría servido demasiado. Esta respuesta está lejos de la que dio la Corte al Informe Rettig en 1991. Sostuvo en esa oportunidad: "En resumen, esta Corte estima que la Comisión [Rettig], extralimitándose en sus facultades, formula un juicio en contra de los Tribunales de Justicia, apasionado, temerario y tendencioso producto de una investigación irregular y de probables prejuicios políticos...". Nada dijo la Corte sobre no haber hecho lo suficiente 
frente a las violaciones de los derechos de las personas. Por el contrario, se limitó a decir que hizo todo lo que la ley ordenaba, sometiéndose a ella como era su deber ${ }^{3}$.

Las respuestas de las Fuerzas Armadas transcritas más arriba también son hoy muy distintas a las que dieron al Informe Rettig ${ }^{4}$. El contraste es particularmente patente en el caso del Ejército, que en 1991 afirmó:

... el Ejército, en aras del prestigio y dignidad elementales de la institución, manifiesta su fundamental discrepancia con el Informe de la Comisión Nacional de Verdad y Reconciliación y le niega tanto validez histórica como jurídica... El Ejército de Chile declara solemnemente que no aceptará ser situado ante la ciudadanía en el banquillo de los acusados, por haber salvado la libertad y la soberanía de la patria a requerimiento insistente de la civilidad... Finalmente, el Ejército de Chile, dado el profundo análisis efectuado al Informe de la Comisión Nacional de Verdad y Reconciliación, cuyas conclusiones han sido expuestas en esta oportunidad, expresa que ésta es la opinión oficial definitiva de la institución en esta materia.

La respuesta del Ejército en el año 2004, demuestra que esta opinión oficial de 1991 no fue, en ningún caso, "definitiva". Y mal podría haberlo sido si se considera que después el propio Ejército, en el año 2000 y a consecuencia de la llamada "Mesa de Diálogo", reconoció haber arrojado restos de personas al mar ${ }^{5}$. Es difícil pensar en una valoración retroactiva del Informe Rettig más fuerte que ésta.

Hay, entonces, notables diferencias entre las reacciones de las Fuerzas Armadas y de la Corte Suprema ante los dos informes que forman parte de la justicia transicional intentada en Chile a partir del cambio de régimen político en 1990. La evolución del escenario político entre las fechas que marcan ambos informes puede explicar en buena parte esas diferencias. Lo que resulta más interesante, sin embargo, es que, a pesar del tiempo transcurrido y de la evolución del contexto político, la reacción del público no muestra cambios tan grandes. Por el contrario, y a diferencia de las instituciones, el público se ha mantenido estable.

\section{El público}

En 1991, algunos días después de haberse dado a conocer el Informe Rettig, la encuesta del Centro de Estudios Públicos (CEP) preguntó: "Como usted sabe, en los últimos días se ha dado a conocer el Informe Rettig. ¿Cómo evalúa usted la posición que ha tenido el Presidente Aylwin en materia de Derechos Humanos?" Las respuestas "positiva" $(40,7 \%)$ y "muy positiva" $(22,7 \%)$ sumaron $63,4 \%$, la respuesta "ni bien ni mal" alcanzó un 25,7\%, mientras que las respuestas "negativa" $(5,1 \%)$ y "muy negativa" (1\%) sumaron sólo un 6,1\%.

Acto seguido, la encuesta inquirió: "Hay personas que piensan que la publicación de los hechos descritos en el Informe Rettig será beneficiosa para Chile. También hay personas que creen que la publicación de estos hechos será perjudicial. ¿Qué piensa usted? La publicación del Informe Rettig ¿será beneficiosa o perjudicial para Chile?" La alternativa "será beneficiosa" acumuló un $63,4 \%$ de las
3 Véase "Respuesta de la Corte Suprema al Informe de la Comisión Nacional de Verdad y Reconciliación", en Estudios Públicos n. 42, Otoño 1991, pp. 237 250. Disponible también en www.cepchile.cl

4 Véase "Respuestas de las Fuerzas Armadas y de Orden al Informe de la Comisión Nacional de Verdad y Reconciliación", en Estudios Públicos n. 41, Verano 1991, pp. 449-504. Disponible también en www.cepchile.cl

5 Para los acuerdos de la "Mesa de Diálogo", véase "Acuerdo de la Mesa de Diálogo sobre Derechos Humanos", en Estudios Públicos n. 79, Invierno 2000, pp. 481-487. Disponible también en www.cepchile.cl 
6 Véase Estudio Social de Opinión Pública, marzo 1991, Documento de Trabajo 156, junio 1991. Disponible también en www.cepchile.cl

7 Véase Centro de Estudios Públicos (CEP), Estudio Nacional de Opinión Pública n. 20, Tercera Serie, diciembre 2004, Documento de Trabajo $\mathrm{n}$. 358, enero 2005.

También disponible en www.cepchile.cl respuestas, mientras que la alternativa "será perjudicial" alcanzó un $20,1 \%$, y "no sabe/no contesta" un $13,5 \%{ }^{6}$.

En diciembre del año 2004, poco después de haberse dado a la publicidad el Informe Valech, la Encuesta CEP volvió a preguntar al público por sus reacciones. A la pregunta " $i \cup d$. cree positivo o negativo que se haya dado a conocer este informe?", un $71 \%$ de los encuestados lo respondió "positivo", un 13\% "negativo" y un 16\% "no sabe/no contesta". También preguntó "Cuando el Presidente Lagos dio a conocer este informe a la ciudadanía habló de la necesidad de "sanar y no reabrir heridas. ¿Ud. cree que este informe ayuda a cerrar las heridas o ayuda a reabrir heridas del pasado?" Un 51\% respondió que ayuda a reabrirlas y un $31 \%$ a cerrarlas, mientras que un $18 \%$ no sabe/no contesta.

Esa proporción es comprensible, pues, debido al largo silencio y a una porfiada lógica de negación, las heridas del pasado no han podido cicatrizar del todo. Cualquier revisión del pasado, por tanto, y de los hechos que causaron esas heridas, implica necesariamente "reabrirlas". Algo de esto se percibe en la respuesta a otra pregunta de la misma encuesta CEP: "Mirando el futuro, ¿cree Ud. que con el tiempo este informe permitirá generar más confianza y paz social entre los chilenos?" Un $53 \%$ contestó que sí, contra un 30\% que contestó no, y un 17\% no sabe/no contesta ${ }^{7}$.

Estas respuestas, unidas al $71 \%$ que consideró "positiva" la publicación del Informe Valech, revelan la existencia de un cierto sentido común que percibe la necesidad de echar luz sobre nuestra historia reciente, a fin de poder volver confiados la vista hacia el futuro. Es decir, un cierto sentido común que percibe la necesidad de intervenir heridas mal cerradas, para que puedan, finalmente, cicatrizar. 